\title{
CRITICAL FIELD FOR SUPERCONDUCTIVITY AND LOW - TEMPERATURE NORMAL-STATE HEAT CAPACITY OF TUNGSTEN
}

B. B. Triplett, N. E. Phillips, T.L. Thorp, D. A. Shirley, and W.D. Brewer

March 1973

Prepared for the U.S. Atomic Energy

Commission under Contract W-7405-ENG-48

\section{TWO-WEEK LOAN COPY}

This is a Library Circulating Copy which may be borrowed for two weeks. For a personal retention copy, call

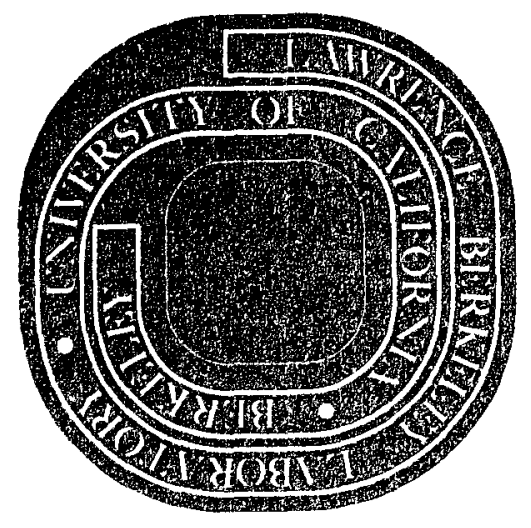
Tech. Info. Division, Ext. 5545 


\title{
Crilical Field for Superconductivity and Low-Temperature Nomnal-State Heat Capacity of l'ungsten*
}

\author{
3. B. Triplett, ${ }^{\dagger}$ N. E. Phillips, T. L. Thorp ${ }^{\dagger}$, \\ D. A. Shirley, and W. D. Brewer ${ }^{\dagger}$ \\ Lawrence Berkeley Laboratory \\ and Department of Chemistry, \\ University of California \\ Berkeley, California 94720
}

\begin{abstract}
We have measured the critical magnetic field for superconductivity in tungsten from 5.5 to $15 \mathrm{mK}$ using a $\gamma$-ray anisotropy thernometer, and we have measlired the heat capacity between 0.35 and $25 \mathrm{~K}$. Analysis of the data gives $\mathrm{H}_{\mathrm{O}}=1.237$ De for the $0 \mathrm{~K}$ critical field, $\mathrm{T}_{\mathrm{C}}=16.0 \mathrm{mK}$ for the critical temperature, $\gamma=1.008 \mathrm{~mJ} / \mathrm{mole} \mathrm{K}^{2}$ for the coefficient of the electronic heat capacity, and $\theta_{0}=383 \mathrm{~K}$ for the $0 \mathrm{~K}$ Debye temperature. The measured values of the critical field $\mathrm{H}_{\mathrm{C}}$ are consistently higher than those reported by Black, Johuson and Wheatley (BJW) on the CMN temperature scale, but the temperature dependence is similar. This discrepancy and the temperature dependence of $\mathrm{H}_{c}$ suggest that both sets of He data are affected by magnetic impuritics. Use of the calorimetric $\checkmark$ value permits an improved test of the CMN temperature scale with the very low temperature $\mathrm{H}_{\mathrm{C}}$ data obtained by $\mathrm{BJW}$.
\end{abstract}




\section{INTRODUCTION}

Superconductivity in tungsten was discovered by Gibson and Hein. 1 Experimental problems prevented an accurate determination of the critical temperature $\mathrm{T}_{\mathrm{C}}$ but, by comparison with the magnetic susceptibility of chromium potassium alum, they estimated upper and lower 1 imits of 11 and $5 \mathrm{mK}$. Johnson et a1. ${ }^{2}$ confirmed the existence of a superconductivity transition at $\mathrm{T}_{\mathrm{C}} \approx 12 \mathrm{mK}$ and measured the critical field $\mathrm{H}_{\mathrm{C}}$. Their measurements were referrcd to the magnetic temperature scale $T^{*}$ (proportional to the reciprocal of the magnetic susceptibility) for a right circular cylinkler with height equal to dianeter of $\mathrm{GN}\left[\mathrm{Ce}_{2} \mathrm{Mg} \mathrm{g}_{3}\left(\mathrm{NO}_{3}\right)_{12}\right.$. $\left.24 \mathrm{H}_{2} \mathrm{O}\right]$. A third, nore extensive series of measurements of the temperature dependence of $\mathrm{H}_{\mathrm{C}}$ has been described by $\mathrm{Black}^{3}$ and by Black, Johnson and Wheatley, ${ }^{4}$ hereafter referred to as BJW. They used the same OMN temperature scale, but improved the thermal contact between the tungsten sample and the $\mathrm{CMN}$, and found $\mathrm{T}_{\mathrm{C}}=15.4 \mathrm{mK}$.

The CMN temperature scale (we use this term to designate the magnetic temperature measured with powdered $\mathbb{C N N}$ and the geometry described above) is of considerable interest because it is the basis for a number of measurements ${ }^{5}$ of the properties of liquid ${ }^{3} \mathrm{He}$ and dilute solutions of ${ }^{3} \mathrm{He}$ in ${ }^{4} \mathrm{He}$. The observed temperature dependence of $\mathrm{H}_{\mathrm{C}}$ for tungsten has been discussed ${ }^{3,4}$ as a test of the accuracy with which this scale reproduces the thermodymamic temperature scale. The test is based on the thermodynamic relation

$$
\mathrm{dH}_{\mathrm{C}}^{2} / \mathrm{dT}^{2}=-(4 \pi / N \mathrm{~T})\left[\mathrm{S}_{\mathrm{N}}(\mathrm{T})-\mathrm{S}_{\mathrm{S}}(\mathrm{T})\right]
$$


where $S_{S}$ and $S_{N}$ are the superconducting - and normal-state molar entropies and $V$ is the nolar volume, and on the BCS expression ${ }^{6}$ for $H_{C}(T)$. Eq. (1) was used in the low-temperature limit in which $S_{N}(T)-S_{S}(T) \sim T$, where $\gamma$ is the cocfficient of the electronic heat capacity. With that approximation (reglect of all contributions to $S_{S}-S_{N}$ except the nomnal-state clectronic entropy) $\mathrm{Eq} .(1)$ can be integrated to give

$$
\mathrm{H}_{\mathrm{C}}^{2}=\mathrm{H}_{\mathrm{O}}^{2}-(4 \pi \mathrm{r} / \mathrm{V}) \mathrm{T}^{2}
$$

Possible discrepancies between $T^{*}$ and $T$ are usually represented by

$$
\Delta \equiv \mathrm{T}-\mathrm{T}^{*}
$$

With $\Delta=0$, Bjiv found a linear relation between $\mathrm{H}_{\mathrm{C}}{ }^{2}$ and $\mathrm{T}^{2}$ for $3 \leq \mathrm{T} \leq$ $4.5 \mathrm{mK}$. The slope of $\mathrm{H}_{\mathrm{c}}{ }^{2}$ vs. $\mathrm{T}^{2}$ corresponded to $\gamma=0.90 \mathrm{~mJ} / \mathrm{mole} \mathrm{K}^{2}$, in reasonable agreement with some recent heat capacity measurements 7,8 which give $\gamma$ values of 0.84 and $0.95 \mathrm{~mJ} / \mathrm{mole} \mathrm{K}^{2}$. Above $4.5 \mathrm{mK}$ where, according to the BCS theory, Eq. (2) is not accurate, BJW analysed their data using different constant values of $\Delta$. The choice $\Delta=0 \pm 0.2 \mathrm{mK}$ gave significantly better fits to the BCS theory than did other constant values of $\Delta$. It was concluded ${ }^{3,4}$ that large values of $\Delta$ (of the order of $1 \mathrm{mK}$ ) which have been suggested by other work ${ }^{9}$ were inconsistent with the $H_{C}$ measurements and that for $\mathrm{T} \geqslant 3 \mathrm{mK}, \Delta \approx-0.01 \cdot \mathrm{mK}$ if the criterion of best fit to the PCS theory is accepted. At temperatures below $3 \mathrm{mK}$, deviations from a linear dependence of $\mathrm{H}_{\mathrm{C}}{ }^{2}$ on $\mathrm{T}^{* 2}$ were observed and were attributed to discrepancies between $\mathrm{T}^{*}$ and $\mathrm{T}$. 
The tungsten critical field measurements reported here were originally undertaken to test apparatus that was used for a search ${ }^{10}$ for superconductivity in lithium and magnesium. $\mathrm{H}_{\mathrm{c}}$ was measured as a function of the temperature indicated by $\gamma$-ray anisotropy thermometers. The importance of the value of $\gamma$ as a test of the thermodynanic consistency of the $H_{c}$ data and the discrepancies between previously reported $\gamma$ values suggested that a new heat capacity measurement would be useful. The heat capacity was therefore measured between 0.35 and $25 \mathrm{~K}$. The results give a new set of values for the parameters characterising the lattice and electronic heat capacities and the superconducting transition in tungsten. Furthermore, comparison with the earlicr $H_{c}$ measurements 3,4 gives an indirect but still interesting comparison of the $\mathrm{aN}$ and $\gamma$-ray anisotropy tomperature scales.

\section{SAMPLES}

The tungsten samples used in this work and by BJW were all purchased from Scmi-Flements Inc. ${ }^{11}$ They all had the same nominal purity, $99.999 \%$, but the residual resisitivities of the various samples differed considerably. Table I shows the measured resistivity ratios as we1l as ratios corrected for the effects of current and size dependence. Since the samples used in this work were polycrystalline and had higher resistance ratios than the single crystal used by BJW, they can be assumed to have lower levels of impurities. 


\section{HEAT CAPACITY MEASUREMENTS}

\section{A. Apparatus and Experimental Techniques}

The tungsten sample used in the heat capacity measurements weighed $80 \mathrm{~g}$. It was attached to the mounting thread at the bottom of the sample holder-thermometer-heater assembly shown in Fig. 1 by a threaded copper bushing. The sample itself was not threaded but was slightly tapered on the mounting end and jammed into the bushing. The differential themal contraction produced good themal contact. (No thermal bonding agent was necessary, and none was used.) Thermal equilibrium in the sample-sample holder system was always attained more rapidly than the time constant of the measuring instruments, approximately $0.3 \mathrm{sec}$. The thermometer was not superheated perceptibly above the final sample temperature with any heater power used in the measurements. The heat capacities of the sample holder and copper bushing were determined in separate experiments.

Thermal contact between the sample holder and the ${ }^{3} \mathrm{He}$ pot of a ${ }^{3} \mathrm{He}$ evaporation refrigerator was made by a mechanical heat switch. The jaws of the switch were attached to the pot by flexible copper wires and closed on the heat switch wire of the sample holder. The pot could be regulated at any temperature between $0.3 \mathrm{~K}$ and $25 \mathrm{~K}$. At temperatures below $1 \mathrm{~K}$ the heat of vaporization of the ${ }^{3}$ Ile was balanced by the heat leak from the ${ }^{4} \mathrm{He}$ bath at $1 \mathrm{~K}$ and an automatically regulated electrical heat input. At temperatures above $1 \mathrm{~K}$ the electrical heat input balanced the heat leaking out to the bath. No exchange gas was used in cooling the samplo below $77 \mathrm{~K}$, and no lle exchange gas was used at any tine. 
A superconducting solenoid (not shown in Fig. 1) was located in the ${ }^{4}$ He bath and could produce ficlds up to $38 \mathrm{k} 0 \mathrm{e}$ on the sample. The stray magnetic field on the gemaniun thernoneter with 38 k0e at the sanple was reduced to approximately 1 oe by a mumetal shield surrounding the themolicter (also not show in Fig. 1). Wlthout this shield the stray field would have been approxinately $1000 \mathrm{e}$.

The germanium resistance themometer was calibrated in a different cryostat that was designed for the purpose. The calibration was based on $T_{58}$, the 1958 "He vapor pressure scale, ${ }^{13}$ between 1.2 and $4.2 \mathrm{~K}$ and the magnetic temperature of a spherical single crystal of CrN below 12. $\mathrm{K}$. Above $4.2 \mathrm{~K}$, the themometer was compared with a constant-volume gas thermometer, which was referred (at $20 \mathrm{~K}$ ) to a platinum themometer calibrated on the NBS (1955) scale. ${ }^{14}$. The gas thermometcr gave temperatures $4 \mathrm{mK}$ lower than $T_{58}$ at $4.2 \mathrm{~K}$, but the discrepancy was within the uncertainty associated with the virial coefficient corrections. (To obtain good precision, a rather high filling pressure had been used.) The heat capacity data are reported on a scale that agrees with $\mathrm{T}_{58}$ at $4.2 \mathrm{~K}$ and with the NBS (1955) scale at $14 \mathrm{~K}$. In the intervening region the scale was interpolated using both the gas thermometer data and a thermoneter calibrated on the NBS acoustic scale ${ }^{15}$ (which is $10 \mathrm{mK}$ higher than $\mathrm{T}_{58}$ at $4.2 \mathrm{~K}$ ) as guide's.

The heat capacities of various copper samples have been measured with the same sample holder-thermometer-heater assembly ${ }^{16}$ and the results are generally in good agreement with other recent measurenents. 17,18 For pure copper $\gamma$ was estimated to be $0.693 \mathrm{mb} / \mathrm{molc} \mathrm{K}^{2}$. (For the purest 
sample actually studied, which contained approximatcly 2 at ppon of iron, $\gamma$ was $0.695 \mathrm{~mJ} / \mathrm{mole} \mathrm{K}^{2}$.) Between 1 and $22 \mathrm{~K}$, the total heat capacity of copper detcrmined in these measurements agreed to within $0.5 \%$ with the reference equation ${ }^{17}$ found to represent several other independent measurenents. That equation is a1so in good agreement with two more recent sets of data that were not considered in its derivation. 19,20

\section{E. Results and Comparison with Other Measurements}

The heat capacity was measured in zero magnetic ficld and in $38 \mathrm{k} 0 \mathrm{e}$. The high field measurcments were made to test for a possible contribution to the heat capacity associated with magnetic impurities. As show in Figs. 2 and 3 , any difference between the zero-field and $38 \mathrm{k0e}$ heat capacities is not large compared with the scatter of the data. This shows that the heat capacity is not affected by magnetic impurities that have Kondo temperatures or spin-spin ordering temperatures of the order of a few $\mathrm{K}$ or lower. For impurities for which these characteristic temperatures are high, the heat capacity contribution per impurity is sma11 at low temperatures. $\Lambda$ significant contribution to the heat capacity by impurities of this type is precluded by the known low total impurity concentration.

With the usual assumptions, the low-temperature heat capacity of a normal metal is the sum of the electronic heat capacity, $C_{E}=\gamma \mathrm{T}$, and the lattice heat capacity, $C_{L}=A_{3} T^{3}+A_{5} T^{5}+\cdots$. Therefore,

$$
C=C_{E}+C_{L}=\gamma \Gamma+A_{3} T^{3}+A_{5} T^{5}+\cdots
$$


and the separation of $C_{L}$ and $C_{L}$ depends on fitting the data with Lq. (4). Both graphical methods, illustrated in Figs. 2 and 3, and least-squares Incthods of analysis have been used. The values obtained for the various paraneters in Eq.(4) dopend on the temperature interval included in the analysis and their accuracy appears to be limited by temperature scale crrors. Least squarcs fits of the data to a number of expressions of the form of $\mathrm{Eq}$. (4) have shown that the onission of the $\mathrm{T}^{5}$ term does not significantly reluce the rms deviation. The data can be fitted with an rms deviation of $0.51 \%$ with only the $\mathrm{T}, \mathrm{T}^{3}$, and $\mathrm{T}^{7}$ terms. The deviations are systematic and, at some temperatures, up to $1 \%$ magnitude, as illustrated in Fig. 3. However, they are similar in temperature dependence and manitude to the deviations of the heat capacity of copper from an expression that included $\mathrm{T}, \mathrm{T}^{3}, \mathrm{~T}^{5}$, and $\mathrm{T}^{7}$ terns. For this reason we believe that the deviations of $\mathrm{C}$ from the three-term fit are largely a reflection of errors in the temperature scale, and that the best estimate of $A_{7}$ is obtained from a fit of this type or from a graphical analysis of the type illustrated in Fig. 3. The rms deviation is reduced to $0.45 \%$ by inclusion of $\mathrm{T}^{9}$ and $\mathrm{T}^{11}$ terms, and the deviations are nore nearly random, but the corresponding values of $A_{7}, A_{9}$, and $A_{11}$ probably have no relation to the properties of tungsten. The coefficients determined by these fits are given in Table II. For the last fit given in Table II, only eleven points, nine of them below $1 \mathrm{~K}$, deviate fron the equation by $0.5 \%$ or morc. The values of $\gamma$ obtained by various least-squares fits to liq.(1) are very similar to the value, $1.008 \mathrm{~mJ} / \mathrm{mole} \mathrm{K}^{2}$, given by the graphical analysis of the below- $4 \mathrm{~K}$ data shown in Fig. 2. The values of $A_{3}$ given by the least-squares fits and 
by the graphical analysis in Fig. 2 are all higher than that given by the graphical analysis of Fig. 3, in which more weight is given to higher temperature data. This discrepancy is apparently associated with an inconsistency between $\mathrm{T}_{58}$ and the scalc used at higher temperatures. Suggested values of the various paraneters are: $\gamma=1.008 \pm 0.010$ $\mathrm{mJ} /$ mole $\mathrm{K}^{2}$ (from Fig. 2); $A_{3}=0.0346 \pm 0.0006 \mathrm{~mJ} / \mathrm{mole}^{\mathrm{K}^{4}}$ (an average of values from Figs. 2 and 3 and from least-squares fits); $A_{5}=0 \pm 2 \times 10^{-6}$ $\mathrm{mJ} / \mathrm{mole} \mathrm{K}^{6}$ (from plots of $\mathrm{C}_{\mathrm{L}} / \mathrm{T}^{3}$ vs. $\mathrm{T}^{2}$ and least-squares fits); $\mathrm{A}_{7}=$ $2.8 \pm 0.5 \times 10^{-8} \mathrm{~mJ} / \mathrm{mole} \mathrm{K}^{8}$ (from Fig. 3). The indicated uncertainties are essentially guesses as to the possible magnitudes of systematic errors, but they are intended to be generous. The value of $A_{3}$ corresponds to a $0 \mathrm{~K}$ Debye characteristic temperature $\theta_{0}=383.0 \pm 2.2 \mathrm{~K}$.

Several other measurements of the low temperature heat capacity of tungsten have been reported recently. Maita ${ }^{7}$ found $\gamma=0.84 \mathrm{~mJ} /$ mole $K^{2}$ and Bucher, Heiniger and Muller ${ }^{8}$ report $\gamma=0.95 \pm 0.05$ and $\theta_{0}=396 \pm 10$. Our measurements are in reasonable agreement with the latter, in view of the estimated uncertainties, but there appears to be a substantial disagreement with the former (the data have not been reported in detail so there is no basis for estimating the probable error). Our measurements are also in good agreement with measurements between 4 and $15 \mathrm{~K}$ by Waite, Craig and Wallace ${ }^{21}$ who found $\gamma=1.1 \pm 0.1$ and $\Theta_{0}=378 \pm 7 \mathrm{~K}$. Ordinarily, measurements in that temperature range would not give reliable values of $\gamma$ or $\theta_{0}$. However, for tungsten $\Theta_{0}$ is relatively high (the electronic heat capacity is $60 \%$ of the tota 1 at $4 \mathrm{~K}$ ) and the $\mathrm{T}^{3}$ approximation for the lattice heat capacity is 
valid to above $10 \mathrm{~K}$. For these reasons it is quite possible to obtain accurate values of $\gamma$ and $\theta_{0}$ from measurenents above $4 \mathrm{~K}$.

\section{CRITICAL FIFLD MEASURELUVIS}

\section{A. Apparatus and Experimental Techniques}

The tungsten sample used in the critical field measurements was a $1 / 8$ in. diancter rod 1.3 in. 1ong. The sample was placed in thermal contact with a slurry of powdered OW through a bundle of approximately 5000 \#40 All Heavy Formex insulated copper wires that were potted in Epibond $100 \mathrm{~A}$ to form a rigid stalk. Contact between the stalk and the sample was made by grinding the end of the stalk to form a large flat area at a sharp angle to its axis. One end of a strip of copper foil that was divided into narrower strips at both ends was tied to the flat on the stalk with fine copper wires and a heavy copper layer was electroplated over the narrow strips and the intervening exposed areas of the flat. The other end of the strip was attached in a similar way to a gold layer bonded to the tungsten sample. The gold layer was produced by evaporating a layer of gold $0.4 \mathrm{in}$. 1ong at one end of the sample and partially diffusing the gold into the tungsten by heating at $1200^{\circ} \mathrm{C}$ for approximately $1 / 2 \mathrm{hr}$. It is estimated that the gold penetrated to a depth of the order of $0.1 \mathrm{~nm}$.

Temperatures were measured with a single crystal ${ }^{6} \mathrm{Co}$ Co nuclear oricntation thermometer that was attached by clectroplating to a lower flat on the stalk. The sample was cooled by simultaneous demagnetization 
of the GMN and a chromium potassium alum guard salt from $46 \mathrm{k} 0 \mathrm{e}$ and $1 \mathrm{k}$. The magnetizing field was produced by a superconducting solenoid in the $1 \mathrm{~K}$ bath that was raised above the liquid helium after conpletion of the denagnetization. The solenoid became nomal within approximately $15 \mathrm{~min}$ of the time it was raised, and was also a considerable distance from the sample after this operation. No other materials that would have become superconducting at their working temperatures were used in the apparatus. The superconducting-normal transition was detected by mutual inductance coils coupled to the sample. A $17 \mathrm{~Hz}, 3$ moe rms primary field was used and the detection system gave a signal to noise ratio of 50 (time constant $3 \mathrm{sec}$ ). The transitions were observed at approxinately constant temperature by sweeping an axial DC field produced by a separate winding on the mutual inductance coil assembly. Low noise current for the winding was provided by a voltage progranmable current supply. The experimental arrangement is described in more detail in Reference 10.

Several indications of the adequacy of the thermal contact between the sample and thernometer were obtained. The most direct is that increasing the primary field to $21 \mathrm{moe}$ rms had no observable effect on the measured critical fields even though it doubled the upward temperature drift of the themometer-sample assembly. The rate at which the transitions occurred also denonstrates good themal contact to the sample. The transitions required a maximum of $5 \mathrm{sec}$ to go to completion. This behavior can be contrasted with that in the experiment by BJW in which the rate of the transition was 1 inited by the Kapitza resistance between the sample and the surrounding ${ }^{3} \mathrm{He}$ bath, and the time required 
for the transition was several minutes. The self heating in the $\gamma$-ray thermometer was approximately $4 \mathrm{erg} / \mathrm{min}$. For experiments limited by a Kapitza resistance between sample and thernometer this would be a relatively high power level, but it should produce a tenperature difference across a clean netallic contact of no more than $10^{-4} \mathrm{mK}$. Although no direct measure of the thernal resistance between the thermometer and the stalk was obtained in this particular experiment, our experience shows that $\gamma$-ray thermoneters mounted in the same way but with twenty times the self heating indicated the same temperature. Stray fields at the sample were compensated with three pairs of Helnholz coils. In the absence of the sanple but with the apparatus at actual operating temperatures, flux-gate nagnetometer and rotating coil gaussmeter probes could be placed at the sample position in a moveable superinsulated hot finger. The field was adjusted to $0 \pm 2$ moe and the field gradients to $0 \pm 1 \mathrm{moe} / \mathrm{cm}$. During critical field measurements the probe was placed 2 in. above the sample and uscd to monitor changes in field. It had been hoped that the stray field would be sufficiently constant that it could be nulled by constant currents in the Helnholz coils that were adjusted before an experinent. However, an unforesecn problem interfered - operation of the $46 \mathrm{k} 0 \mathrm{e}$ solenoid changed the laboratory stray field. Inmediately after demagnetization the axial field at the sample site was 35 m0e greater than it had been before the solenoid was turned on. The stray field decayed to 2 moe during the period required for a series of measurements, but the decay 
was not precisely regular. During the measurements the axial field 2 in. above the sample was compared at intervals with the value deduced by measuring the critical field with opposite polarities of the applied field. The accuracy of the latter method of determining the stray axial field was limited primarily by the temperature drift between measurements. The -two methods of measuring the axial stray field differed by as much as $20 \%$, even when it was greater than 10 moe. In correcting for the stray axial field greater weight was given to the values estimated by observing the transition with applied fields of opposite polarities, but values measured with the probe were uscd for interpolating in time. The uncompensated stray field after a domagnetization also had a horizontal component but it was considerably smaller -- a maximum of 7 moe. It was not possible to monitor this component during the measurenents and no correction has been made for it. The estinated overall accuracy of the critical field measurements is 10 m0e at the lowest temperatures and 2 m0e near $\mathrm{T}_{\mathrm{C}}$.

An additional complication in the critical field measurements was the appearance at the lowest temperatures of a second transition. It occurred at lower critical fields and produced a change in mutual inductance about $1 / 3$ as great as that associated with the main transition. We have been unable to devise a complctely satisfactory explanation for the occurrence of the second transition, but we suspect it was associated with the end of the sample to which the gold diffusion bond was made and which was just outside the secondary coils. Both trinsitions were very sharp and apparently completely independent. The second 
transition, when it occurred, seemed to have no affect on the main transjtion. The data reported here were obtained in a single run that extended to $5.2 \mathrm{mk}$. The points taken below 5.5 mk were complicated by superheating effects as well as by the second transition and have been omitted.

\section{B. Results and Comparison with Other Measurements}

The results of the critical field measurements are shown in Fig. 4 as $\mathrm{H}_{\mathrm{C}}$ vs. $\mathrm{T}^{2}$, and the data below $9 \mathrm{mK}$ are also shom as $\mathrm{H}_{\mathrm{C}}{ }^{2} \mathrm{vs} . \mathrm{T}^{2}$ in Fig. 5. We have used tio different procedures to extrapolate $\mathrm{H}_{\mathrm{C}}$ to $0 \mathrm{~K}$ to obtain $\mathrm{H}_{\mathrm{O}}$. The first method was based on the BCS cxpression for $\mathrm{H}_{\mathrm{C}}$, and the second on Eq. (2).

Tungsten certainly corresponds to the weak-coupling linit treated in the BCS theory, and the deviations of the $\mathrm{H}_{\mathrm{C}}$ data from a parabolic temperature dependence, $\mathrm{H}_{\mathrm{C}}=\mathrm{H}_{\mathrm{O}}\left[\mathrm{I}-\left(\mathrm{T} / \mathrm{T}_{\mathrm{C}}\right)^{2}\right]$, are in qualitative agreement with those predicted by the BCS theory (see Fig. 4). It therefore seems reasonable to base the extrapolation of $H_{C}$ to $0 \mathrm{~K}$ on the BCS expression. As shown in Figs. 4, 5 and $6 \mathrm{a}$, the $H_{c}$ data do fit the BCS theory to within the precision of the measurenents. The quantity plotted in Fig. 6 is the deviation, $\mathrm{D}(\mathrm{t}) \equiv \mathrm{h}-\left(1-\mathrm{t}^{2}\right)$, of the reduced critical field, $h \equiv H_{C} / H_{0}$, from a parabolic dependence on reduced temperature, $t \equiv \mathrm{T}_{\mathrm{T}} \mathrm{T}_{\mathrm{C}}$. The value of $\mathrm{T}_{\mathrm{C}}$ was found by the procedure used by BJW: an approxinate value for $\mathrm{H}_{\mathrm{O}}$ and a high temperature expansion 22 based on BCS theory for $H_{C}(T)$ were used to find a prelininary value of $\mathrm{T}_{\mathrm{C}}$. That value of $\mathrm{T}_{\mathrm{C}}$ and nunerical tables ${ }^{23}$ of the BCS 
functions wre then uscd to adjust $\mathrm{H}_{\mathrm{O}}$ to give better agreenent with the theoretical $D(t)$ at low temperatures. Finally, the new $\mathrm{H}_{\mathrm{o}}$ value was used to recalculate $\Gamma_{C}$. The numerical values are $H_{0}=1.2240 \mathrm{e}$, and $\mathrm{T}_{\mathrm{C}}=15.98 \mathrm{mK}$.

Although the critical field data can be fitted with the BCS theory, an inconsistency becomes apparent when the calorimetric data are included in the comparison. The $\gamma$ value that corresponds to the representation of the critical field data by BCS theory is given by

$$
\frac{2 \pi \gamma \mathrm{T}_{\mathrm{C}}{ }^{2}}{\mathrm{VH}_{\mathrm{O}}{ }^{2}}=1.057,
$$

and is $\gamma=0.94 \mathrm{~mJ} / \mathrm{mole} \mathrm{K}^{2}$. (We have used $\mathrm{V}=9.508 \mathrm{~cm}^{3} / \mathrm{mole}$, as calculated from the lattice parameter ${ }^{24}$ and thermal expansion. ${ }^{25}$ ) This value differs significantly from that determined calorimetrically. The calorimetric value requires larger (negative) slopes of $D(t)$ vs. $t^{2}$ and $\mathrm{H}_{\mathrm{C}}{ }^{2}$ vs. $\mathrm{T}^{2}$ in the $0 \mathrm{~K}$ limit. For example, Eq. (2) requires that $\left[\mathrm{dD}(\mathrm{t}) / \mathrm{dt}^{2}\right]_{t=0}=-\left[\left(2 \pi \gamma \mathrm{T}_{\mathrm{c}}{ }^{2} / \mathrm{VH}_{\mathrm{o}}{ }^{2}\right)-1\right]$; the calorimetric $\gamma$ value gives an initial slope -0.113 , whereas the BCS theory gives -0.057 .

The BCS expression for $\mathrm{H}_{\mathrm{C}}$ and Eq. (2) agree to within $0.2 \%$ for $t \leq 0.3$ (but diverge rapidly at higher temperatures). If $\mathrm{H}_{\mathrm{C}}{ }^{2}$ is extrapolated to $0 \mathrm{~K}$ from our lowest-temperature data with the slope required by Eq. (2) and $\gamma=1.008 \mathrm{~mJ} / \mathrm{mole} \mathrm{K}^{2}$, the value of: $H_{0}$ is increased to 1.237 oe. The values of $D(t)$ are then considerably more negative than predicted by the BCS theory. This interpretation of the 
critical field data is also represented in Figs. 5 and $6 \mathrm{~b}$. It corresponds to a superconducting-state entropy that increases more rapidly with increasing temperature than BCS theory predicts for the values of $\gamma$ and $T_{C}$. If it is assumed that $\|_{C}{ }^{2}$ follows the KC,S curve in Fig. 5 to a lower temperature and the slope changes to the value required by Eq. (2) only at a temperature well below the lowest temperature critical field data, the affect on $\mathrm{H}_{\mathrm{O}}$ and $\mathrm{D}(\mathrm{t})$ is smaller, but the implication for the temperature dependence of the superconducting-state entropy is sinilar. In fact, since $\mathrm{H}_{\mathrm{C}}$ depends only on $\mathrm{S}_{\mathrm{N}}{ }^{-} \mathrm{S}_{\mathrm{S}}$, the $\mathrm{BCS}$ extrapolation of $\mathrm{H}_{\mathrm{C}}{ }^{2}$ to $0 \mathrm{~K}$ indicated in Fig. 5 would be consistont with the calorimetric $\gamma$ value if there were a linear term in the superconducting-state entropy.

The critical field ciata reported by $\mathrm{BH}$ are also represented in Figs. 4-6. (We have corrected their data, according to the formula they suggest, for the effect of the field produced by the $\mathrm{CMN}$ on the tungsten sample, and we have taken their reported valucs of $\mathrm{H}_{\mathrm{O}}$ and $\mathrm{T}_{\mathrm{c}}$ in which this correction is included.) Their $H_{c}$ data are consistent?y lower than ours, and their values for $\mathrm{H}_{\mathrm{O}}$ and $\mathrm{T}_{\mathrm{c}}, 1.15$ de and $15.4 \mathrm{mK}$, are lower by $6 \%$ and $4 \%$ respectively. On the other hand, the relation between their data, BCS theory, and the calorimetric $\gamma$ value is strikingly similar to that found in this work. BJW's data extend below $4.5 \mathrm{nK}$, the tenperature at which BCS theory predicts that liq. (2) becones accurate to $0.2 \%$. Between that temperature and $3 \mathrm{mk}$ their data give a straight line when plotted as $\mathrm{H}_{\mathrm{c}}{ }^{2}$ vs. $\mathrm{T}^{2}$ but deviations occur below $3 \mathrm{mk}$. They attributed the deviations to a nonzero $\Delta$ (Eq. (3)) below 
$3 \mathrm{mK}$ and extrapolated the straight line to $0 \mathrm{~K}$ to obtain $\mathrm{H}_{\mathrm{O}} \cdot \mathrm{T}_{\mathrm{C}}$ was obtained by the extrapolation procedure based on BCS theory described above. As shom in Fig. 6a the values of $D(t)$ found by BJW are sinilar to those found in this work by using BCS expressions to extrapolate to $0 \mathrm{~K}$, and are in good agreenient with BCS theory. Ilowever, the value of $\gamma$ calculated from the $\mathrm{H}_{\mathrm{C}}{ }^{2}$ vs. $\mathrm{T}^{2}$ straight line and Eq. (2) is $0.90 \mathrm{~mJ} /$ mole $K$, also in disagrcement with the calorimetric $\gamma$ value.

\section{DISCUSSION}

\section{A. Critical Field}

Experimental crrors -- either in the measurenent of the critical ficld or in the temperature scales - nay contribute to the difference between our critical field measurements and those by BJW, but there is reason to think that a large part of the difference is a reflection of a real difference in the properties of the two samples. When analyzed in similar ways, both sets of data give similar values for $D(t)$ and for $\gamma$. (The agreement between the $\gamma$ values is not as good as might be expected from critical field measurements made under ideal conditions, but it is very good in view if the special experimental problems associated wi.th the low value of $\mathrm{T}_{\mathrm{C}}$.) As described below, this can easily be understood as a consequence of different impurity levels in the samples, but an understanding on any other basis would require implausible experimental crrors. Jigure 4 shows that the required error is an approximately constant adlitive error in critical field or in the square of the temperature (or some equivalent combination of the two). In both 
sets of measurcments the stray axial field was checked by measuring critical fields with opposite polarities of the applied field and any undected perpendicular field would add vectorially. The apparent difference in $T_{C}$ values is not large compared with the combined estimated uncertainties in temperature at that temperature, but the discrepancy in temperature at the lowest temperatures is well outside reasonable error limits. Furthemore, it is difficult to see how a constant error in the square of the temperature, over the range of temperature involved, could occur in either measurenent.

Concentrations of impurities too low to have a perceptible effect on equilibriun momal-state properties, in particular $\gamma$, can have a substantial. effect on superconducting-state properties and, therefore, on parameters related to the transition. Experimental evidence suggests that low concentrations of nonmagnetic impurities general1y lower $\mathrm{T}_{\mathrm{C}}{ }^{2}{ }^{26}$ The effect is produced by a reduction in the energy of condensation to the superconducting state associated with the energy gap anisotropy in the clean sample and the reduction in electron moan free path. ${ }^{27,28}$ At very low concentrations the reduction in $\mathrm{T}_{C}$ is proportional to the concentration of impurities, but there is a maximum to the reduction, observed for clectron mean free paths short compared with the coherence distance. 27,28 If we assume a typical value for the energy gap anisotropy of tungsten, of the order of a few percent, it appears that this effect cannot account for the difference between our sample and that used by BJW. ${ }^{29}$ Impurities with localized magnetic moments, however, can have a 
greater effect on $T_{C}$ through their reduction of the lifetine of the Cooper pairs, and they also affect the temperaturc dependence of the superconducting state entropy in the way suggested by our critical field measurements when thoy are analyzed in conformity with Eq.(2). Values of $\mathrm{dT}_{\mathrm{C}} / \mathrm{dc}$, where $\mathrm{c}$ is the concentration of magnetic impurities, of the order of 1 to $10 \mathrm{mk} / \mathrm{at}$ ppn have been reported. 30 A magnetic impurity concentration of the order of 1 at ppn is not inconsistent with the heat capacity data, and secms entirely possible for both samples. Since both samples were obtained from the same supplier and that used by BJW had a higher residual resistivity, it is reasonable to consider that the difference in $\mathrm{T}_{\mathrm{C}}$ is associated with a higher concentration of magnetic impurities in BJW's sample.

In the presence of magnetic impurities the superconducting-state entropy increases more rapidly as the temperature increases from zero, and $\mathrm{D}(\mathrm{t})$ is shifted to more negative values than given by BCS theory, particularly at low reduced temperatures. Decker and Finnemore ${ }^{31}$ have calculated $D(t)$ for various values of $T_{C} / T_{C p}$, where $T_{C p}$ is the value of $\mathrm{T}_{C}$ in the absence of magnetic impurities, using an extension ${ }^{32}$ of the Abrikosov-Gorkov ${ }^{33}$ (AG) theory. The calculated $\mathrm{D}(\mathrm{t})$ curves are in good agreement with expcriment for ThGd alloys. ${ }^{31}$ For $\mathrm{T}_{\mathrm{c}} / \mathrm{T}_{\mathrm{cp}}=0.8$ and 0.6 they are reproduced in Fig. $6 \mathrm{~b}$ and it is apparent that they are in qualitative agrement with the critical field data when those data are extrapolated to $0 \mathrm{~K}$ in accord with Eq. (2). [For $T_{C} / T_{C p}$ in the region 0.6 to 0.8 the stperconductor is gapless only near $T_{C}, S_{S}(T)$ varies exponentially with $T$ for $\mathrm{T} \ll \mathrm{T}_{\mathrm{C}}$, and $\mathrm{Eq} .(2)$ is still valid. ${ }^{32,33}$ ]

The prescnce of plausible concentrations of magnetic impurities would thus account in a straightforward way for a large part of the 
discrepancy between our critical field measurements and those by BJW. It would also account for the discreparcy between the calorimetric $\gamma$ value and the value obtained by an analysis of the critical field measurements based on BCS theory. A1tough not suphorted by conclusive evidence, such an interpretation is reasonable, and suggests that the superconductingstate propertics of all sanples of tungsten studied so far are significantly influenced by magnetic impuritics. Detailed information on the impurities in our sanple and in BJW's night permit an estimate of $T_{C p}$ from the two observed values of $\mathrm{T}_{\mathrm{C}}$, but it is not available and would be extremely difficult to obtain for such low impurity concentrations. An approximate upper limit to $\mathrm{T}_{\mathrm{Cp}}$ is suggested by Fig. 60, however. Recalling that the points in that figure represent a probable upper 1 imit to $|D(t)|$, we can say that $T_{\mathrm{Cp}_{\mathrm{p}}}$ might be as high as $20 \mathrm{mK}$. The general shape of $D(t)$ defined by the experimental points suggests that this value may be approximately correct, but the precision of the data do not permit a firm estimate.

\section{B. Electronic leat Capacity}

The measured value of $\gamma$ corresponds to a density of electronic states at the fermi cnergy $N(0)=0.43$ states of both spins/eV atom. Bank structure calculations give the "bare" or "band-structure" density of states $N_{\text {bs }}(0)=N(0) /(1+\lambda)$ where $\lambda$ is the electron-phonon interaction parancter. Mcmillan's ${ }^{34}$ fomula for $T_{c}$ and his suggested approximate value of 0.13 for the coulomb repulsion term $\mu^{*}$ permit an estimate of $\lambda$ 
from the experimental $\mathrm{T}_{\mathrm{c}}$ and $\theta_{0}$. The result is $\lambda=0.27$ which gives $\mathrm{N}_{\mathrm{bs}}(0)=0.34$ states of both spins $/ \mathrm{eV}$ atom. Matheiss ${ }^{35}$ has calculated two values of $\mathrm{N}_{\mathrm{bS}_{\mathrm{S}}}(0), 0.56$ and 0.32 states of both spins/eV atom, using a nomrelativistic augmented-plane-wave (APi) method and two different potentials. Loucks has derived $\mathrm{N}_{\mathrm{bS}}(0)=0.640$ states of both spins/eV atom from a nomrelativistic $\mathrm{APW}$ calculation ${ }^{36}$ and $\mathrm{N}_{\mathrm{bS}}(0)=$ 0.368 states of both spins/eV atom from a relativistic APW calculation. 37 The "experimental" value of $\mathrm{N}_{\mathrm{bs}}(0)$ is sensitive to the value of $\lambda$ and, therefore, to the assumed value of $\mu^{*}$. However, any error intioduced into the experjmental value by the assumed value of $\mu^{*}$ is probabiy smaller than the error in the theoretical values that is apparently associated with uncertainty in the potential.

\section{Lattice Heat Capacity}

The lattice heat capacity of tungsten is shown in Fig. 7 as a plot of the effective Debye temperature $\Theta$ as a function of temperature. $(\Theta$ is defined by equating the experimental hoat capacity data to the Debye heat capacity function of $\theta / T$.) The values of $\theta$ exhibit the usual decrease with increasing tomperature. However, the curve is somewhat unusual in that $\theta$ is constant up to $\theta_{0} / T=30$, corresponding to the small value of $A_{5}$. The solid square in Fig. 7 represents the value of $\Theta_{0}, 384.3 \mathrm{~K}$, calculated from sound velocity measurements. ${ }^{38}$ It agrees with the calorimetric value, $383.0 \mathrm{~K}$, to within the estimated uncertainties. 


\section{CMN Temperature Scale}

If the above interpretation of the critical field data is accepted, the deviations from Eq. (2) of the low-temperature data obtained by BJit can be usal as a test of possible $T\left(T^{*}\right)$ relations for CMN. It is not practical to derive the correct $\mathrm{T}^{\left({ }^{*}\right)}$ relation from such data alone because several different $\mathrm{T}\left(\mathrm{T}^{*}\right)$ relations may give satisfactory agreement with Eq. (2). This is illustrated in Fig. 8 where it is shown that $\Delta=-0.4 \mathrm{mK}$ and $\mathrm{T}^{2} \Delta=9 \mathrm{mK}^{3}$ both give reasonable agreement between the data and Eq. (2.). The latter relation is similar in temperature depen-

dence to that obtained by webb et a1. ${ }^{39}$ with a Johnson noise thennometer, but it gives considerably larger values of $\Delta\left(\mathrm{eg}\right.$. , at $\mathrm{T}^{*}=2.0 \mathrm{mK}, \Delta=$ $1.0 \mathrm{mK}$, compard with $\Delta=0.4 \mathrm{mK}$ from the noise thermometer measurenents). llower, the test of the $\mathrm{T}\left(\mathrm{T}^{*}\right)$ relation based on the critical field data is quite sensitive to the correction for the contribution to the field applied to the tungsten sample from the magnetic moment of the CMN. The $\mathrm{T}^{2} \Delta=9 m \mathrm{~K}^{3}$ estimate was based on a correction proportional to $1 / \mathrm{T}^{*}$ and equal to $2 \%$ at $1 \mathrm{mK}$, but the estinated uncertainty in the correction is $\pm 50^{\circ}$, and use of the largest correction within this range would reduce the value of $\mathrm{T}^{2} \Delta$ obtained from the critical field data (to give $\Delta=0.8 \mathrm{mK}$ at $\mathrm{T}^{*}=2.0 \mathrm{mK}$ ). Furthermore, it is clear that more complicated expressions for $\Delta(T)$ could be found that would give reasonable consistency with Eq.(2) and also with the noise thermometer data. For exanple, $\mathrm{T}^{2}(\Delta+0.3)=3 \mathrm{mK}^{3}$ gives good agrecment with Eq. (2) and also gives $\Delta=0.4 \mathrm{mK}$ at $T^{*}=2.0 \mathrm{mK}$. However, this relation is certainly 
not unique in these respects. On the other hasd, the critical field data are clearly not consistent with a positive, temperature-independent $\triangle$. As proviously noted by Black $^{3}$ such a valic of $\triangle$ increases the curvature of the low-temperature $\mathrm{H}_{\mathrm{C}}{ }^{2}$ vs. $\mathrm{T}^{2}$ plot, but it also tends to lower the value of $\gamma$ deduced from the $\mu_{c}$ data and therefore to increase the discrepancy with the calorimetric value.

\section{SUMMNRY}

The heat capacity of tungsten has been neasured betwcen 0.35 and $25 \mathrm{~K}$. The value of $\gamma, 1.008 \mathrm{~mJ} / \mathrm{mole} \mathrm{k}^{-2}$, is within the rather broad range of previously reported values and is believed to be accurate to 1\%. The valuc of $\theta_{0}, 383 \mathrm{~K}$, is in good agreement with that calculated from elastic constants. In this temperature region the accuracy of the temperature scale limits the accuracy with which the various terms in the latticc heat capacity can be determined, but within this limitation the lattice heat capacity can be represented by a sum of $\mathrm{T}^{3}$ and $\mathrm{T}^{7}$ terms.

The critjcal field for superconductivity in tungsten has been measured between 5.5 and $15 \mathrm{mK}$ using a $\gamma$-ray anistropy thermometer. Analysis of the data gave $\mathrm{H}_{\mathrm{O}}=1.237 \mathrm{0e}$ and $\mathrm{T}_{\mathrm{C}}=16.0 \mathrm{mk}$. The meastred values of ${ }^{\prime} \mathrm{c}$ are consistently higher than those reported by BJW. This discrepancy and discrepancies between the calorimetric $\gamma$ value and the low-tcmperature slopes of $\mathrm{H}_{\mathrm{C}}{ }^{2}$ Vs. $\mathrm{T}^{2}$ suggest that the superconductingstate properties of both samples are influenced by magnetic inpurities. 
The critical ficld data obtained by BJW below 4.5 mK on the powdered $\mathrm{CMN}_{\mathrm{N}} \mathrm{T}^{*}$ scalc were reanalyzed using the calorimetric $\gamma$ value. This analysis confirms that positive temperature independent values of $\Delta=T^{\prime} T^{*}$ are inconsistent with the critical ficld data but shows that $\Delta \neq 0$ at temperatures as high as $4.5 \mathrm{mk}$. The recent noise-thomoneter measurements of $\Delta(T)$ are at least qualitatively consistent with the critical field data. 
REFERENCES

* Work supported by the U. S. Atomic Energy Commission.

$\dagger$ Present address: Department of Physics, Stanford University Stanford, California 94305.

$\div$ Present address: Royal Radar Establislment, Malvern, Worcestershire, U. K.

Present aklress: I. Physics Institute Iree University of Berlin 20 Boltzmannstrasse, 1 Berlin 33, Gennany

1. J. W. Gibson and R. A. Hein, Phys. Rev. I.etters 12, 688 (1964).

2. R. T. Jolnson, O. E. Vilches, J. C. Wheatley, and S. Gygax, Phys. Rev. Letters 16, 101 (1966).

3. W. C. Black, Phys. Res. Letters 21, 597 (1966).

4. W. C. Black, R. T. Johnson, and J. C. Wheailley, J. Low Temp. Phys. 1, 641 (1969).

5. This work has been reviewed recently by John C. Wheatley, in Progress in l.ow Tcimperature Physics, Vol. VI, C. J. Gorter, Ed., North Holland Publishing Company, Nmsterdam, 1970, p. 77.

6. J. Bardeen, L. N. Copper and J. R. Schrieffer, Phys. Rev. 108, $1175(1957)$.

7. J. P. Maita, quoted by T. Il. Geballe, Rev. Mod. Phys. 36, 134 (1964). 
8. E. Fucher, F. Heiniger, and J. Miller, Proceedings of the Ninth Intermitional Conference on Low Temperature Physics, Colunbus, Ohio, 1964, J. G. Inunt, 1). O. Fiwards, I:. J. Milford, and M. Yaqub, eds., Plenum Press, Now York, 1965, p. 1059.

9. B. M. Abrahan and Y. Eckstein, Phys. Rev. Letters 20, 649 (1968); 24, $663(1970)$.

10. T. L. Thorp, et al., J. Low Ternp. Phys. 3, 589 (1970) .

11. Semi-Elements Inc., Saxonburg Blvd., Saxonburg, Pennsylvania.

12. K. H. Berthe1, Phys. Stat. Sol. 5, 159 (1964).

13. F. G. Prickwodde, H. van Dijk, M. Ihrieux, J. R. Clenent, and J. K. Logan, J. Res. Natl. Bur. Std. (U.S.) 64A, 1 (1960) .

14. Temperatures on this scale are $10 \mathrm{mk}$ lower than on the one described by H. J. Hoge and F. G. Brickwedde, J. Res. Natl. Bur. Std. (U.S.) $22,351(1939)$.

15. Harnon P'lumb and George Cataland, Metrologia 2, 127 (1966).

16. B. B. Triplett, Ph.D. thesis, University of California at Berkeley, 1970, umpublished: B. B. Triplett and Noman E. Phillips, Phys. Rev. Letters 27, 1001 (1971), and to be published.

17. D. W. Osborne, H. I. Flotow, and F. Scheiner, Rev. Sci. Instr. $38,159(1967)$

18. A compilation of recent measurements is given by Norman E. Phillips, Critical Reviews in Solid State Sciences 2, 467 (1971).

19. T. C. Cetas, C. R. Tilford, and C. A. Swenson, Phys. Rev. 174, $385(1968)$. 
20. A. J. Leadbetter and K. E. Wycherley, J. Chem. Thermodynamics 2, $855(1970)$.

21. T. R. Waitc, R. S. Craig, and W. E. Wallace, Plys. Rev. 104, $1240(1956)$

22. J. R. Clem, Ann. Phys. (N.Y.) 40, 268 (1966).

23. B. Mühlschlegel, Z. Physik 155, 313 (1959).

24. W. Parrish, Acta Cryst. 13, 838 (1960).

25. R. J. Corrucini and J. J. Gniewek, NBS Monograph 29, U. S. Government Printing office, Washington, 1961.

26. E. A. Lynton, B. Serin, and M. Zucker, J. Phys. Chem. Solids $\underline{3}$, 165 (1957); G. Chanin, E. A. Lynton, and B. Serin, Phys. Rev. 114, 719 (1959).

27. P. W. Anderson, J. Phys. Chem. Solids 11, 26 (1959).

28. David Markowitz and Leo P. Kadanoff, Phys. Rev. 131, 563 (1963).

29. This estinate was based on the quantitative theory developed in ref. 28, values of normal-state parameters reported by E. Fawcett and 1. Griffiths, J. Phys. Chem. Solids 23, 1631 (1962), and the resistivity ratios of the samples.

30. See, for cxample, G. Boato, G. Gallinaro, and C. Rizzuto, Phys. Rev. 113353 (1.960) and references therein; klaus Schwidtal, Z. Physik 158, 563 (1960).

31. W. R. Decker and D. K. Finnemore, Phys. Rev. 172, 430 (1968).

32. S. Skalski, O. Betbeder-Matibet, and P. R. Weiss, Phy's. Rev. 136, A1.500 (1964). 
33. A. A. Abrikosov and L. P. Gor'kov, 2h. Eksperim. i Teor. Tiz. 39, 178 (1960) [linglish trans1.: Soviet Ihysics-JFll 12, 1243 (1961)].

34. H. L. MeMillan, Phys. Rev. 167, 3.31 (1968).

35. J. M. Mathojss, Phys. Rev. 139, A1893 (1965).

36. T. L. Loucks, Phys. Rov. 139, A1181 (1965).

37. T. L. Loucks, Phys. Rev. 143, 506 (1966).

38. F. H. Featherston and J. R. Neighbours, Phys. Rev. 130, 1324 (1963).

39. R. A. Webb, R. P. Giffard, and J. C. Mhcatley, Phys. Letters 41A, 1 (1972). 
Table I. Properties of tungsten sampies.

\begin{tabular}{|c|c|c|c|}
\hline Measurement & $\begin{array}{l}\text { Measured } \\
\text { Resistivity Ratio }\end{array}$ & $\begin{array}{l}\text { Intrinsic } \\
\text { Resistivity Ratio }\end{array}$ & $\begin{array}{l}\text { Physical Form } \\
\text { of Sample }\end{array}$ \\
\hline BJW, critical field & 7,500 & & $\begin{array}{c}\frac{1 "}{8} \text { diam. single } \\
\text { crystal }\end{array}$ \\
\hline This work, heat capacity & $57,000^{\mathrm{a}}$ & 67,000 & $\frac{1}{4} "$ diam. polycrystal \\
\hline This work, critical field & 17,000 & 19,500 & $l_{8}^{\prime \prime}$ diam. polycrystal \\
\hline
\end{tabular}

a This value is the average of potentiometric and eddy current measurements on different sections of the rod. The two values differed by $20 \%$.

$\mathrm{b}$ Calculated from the measured ratio from the data in Ref. 12 . 
Table II. Coefficients in Eq. (4) obtained by least-squares fits.

\begin{tabular}{|c|c|c|c|c|c|c|c|}
\hline $\begin{array}{l}\text { Exponents of } \\
\text { inciuded } \\
\text { terms }\end{array}$ & $\begin{array}{c}\text { ms } \\
\text { deviation } \\
(\%)\end{array}$ & $\begin{array}{c}y \\
\left(\mathrm{~mJ} / \mathrm{mole} \mathrm{K}^{2}\right)\end{array}$ & $\begin{array}{c}\mathrm{A}_{3} \\
\left(\mathrm{~mJ} / \mathrm{mole} \mathrm{K}^{44}\right)\end{array}$ & $\begin{array}{c}\mathrm{A}_{5} \\
\left(\mathrm{~mJ} / \mathrm{mole} \mathrm{k}^{5}\right)\end{array}$ & $\begin{array}{c}A_{7} \\
\left(\mathrm{~mJ} / \text { mole } \mathrm{K}^{8}\right)\end{array}$ & $\begin{array}{c}\Lambda_{g} \\
\left(\mathrm{~m}^{\top} / \mathrm{mole} \mathrm{K}^{10}\right)\end{array}$ & $\begin{array}{c}\mathrm{A}_{1:} \\
\left(\mathrm{mJ} / \mathrm{mole} \mathrm{K}^{12}\right)\end{array}$ \\
\hline $1,3,7$ & 0.51 & 1.000 & $3.46 \times 10^{-2}$ & & $2.66 \times 10^{-8}$ & & \\
\hline $1,3,5,7$ & 0.50 & 1.009 & $3.48 \times 10^{-2}$ & $-2.14 \times 10^{-5}$ & $3.05 \times 10^{-8}$ & & \\
\hline $1,3,7,9$ & 0.51 & 1.009 & $3.46 \times 10^{-2}$ & & $2.56 \times 10^{-8}$ & $1.88 \times 10^{-12}$ & \\
\hline $1,3,5,7,9$ & 0.47 & 1.008 & $3.51 \times 10^{-2}$ & $-1.01 \times 10^{-5}$ & $7.07 \times 10^{-8}$ & $-5.14 \times 10^{-11}$ & \\
\hline $1,3,7,9,11$ & 0.45 & 1.009 & $3.48 \times 10^{-2}$ & & $-1.78 \times 10^{-8}$ & $2.11 \times 10^{-12}$ & $-2.45 \times 10^{-13}$ \\
\hline $1,3,5,7,9,11$ & 0.45 & 1.008 & $3.48 \times 10^{-2}$ & $-4.58 \times 10^{-7}$ & $-1.42 \times 10^{-8}$ & $2.01 \times 10^{-10}$ & $-2.36 \times 10^{-13}$ \\
\hline
\end{tabular}




\section{Figure Captions}

Fjg. 1 The smmple holder-thermoneter-heater assembly. The distance between the samplo mounting thread and the thermoineter is approxinatejy $22 \mathrm{~cm}$.

Fig. 2 The heat capacity of tungsten as $\mathrm{C} / \mathrm{T}$ vs. $\mathrm{T}^{2}$ for $\mathrm{T}<4 \mathrm{k}$. The straight line represents a graphical fit to the data in this temperature region.

Fig. 3 The lattice heat capacity of tungsten as $C_{L} / T^{3}$ vs. $T^{4}$ for $\mathrm{T}>4 \mathrm{~K}$. The straight line represents a graphical fit to the data in this temperature region.

Fig. 4 The critical field of tungsten as $\mathrm{H}_{\mathrm{C}} \mathrm{vs} \cdot \mathrm{T}^{2}$. The curves represent BCS theory fitted to the data as described in the text.

Fig. $5^{\circ}$ The critical field of tungsten as $\mathrm{H}^{2}$ vs. $\mathrm{T}^{2}$, for $\mathrm{T}<9 \mathrm{mK}$. The solid curves represent BCS theory fitted to the data as described in the text. The dashed lines represent the liniting slope required by Eq. (2) with $\gamma=1.008 \mathrm{~mJ} / \mathrm{mole} \mathrm{K}^{2}$.

Fig. 6 The critical field of tungston plotted as deviations of the reduced critical field from parabolic temperature dependence vs. the square of the reduced temperaturc. In (a) the values of $\mathrm{H}_{\mathrm{O}}$ wore obtained by fitting to the BCS theory. In (b) the 
values of $\mathrm{H}_{\mathrm{O}}$ were obtained by extrapolating to $0 \mathrm{~K}$ according to $\mathrm{Kq}$. (2) with $\gamma=1.008 \mathrm{~mJ} /$ mole $\mathrm{K}^{-2}$ (j.e. as shown by the dashed Jine in Fig. 6). The solid curves represent BCS theory and the dashed curves AG theory.

fig. 7 The latuice hoat capacity of tungsten plotted as $\theta$ vs. T. The solid square ropresents $\Theta_{0}$ as calculated from elastic constants. The curve represcnts the temperature dependence of $\theta$ corresponding to $A_{3}=3.46 \times 10^{-2} \mathrm{maJ} / \mathrm{nole} \mathrm{K}^{4}, \mathrm{~A}_{7}=$ $2.84 \times 10^{-8} \mathrm{mb} / \mathrm{mole} \mathrm{K}^{8}$, and all other coefficients in $\mathrm{C}_{\mathrm{L}}$ equal to zero.

Fig. 8 Critical field of tungsten as determined by BJW, plotted as $\mathrm{H}_{\mathrm{C}}{ }^{2}$ vs. $\left(\mathrm{l}^{*}+\Delta\right)^{2}$ for various $\Delta(\mathrm{l})$. The straight lines correspond to Eq. (2) and $\gamma=1.008 \mathrm{~mJ} / \mathrm{mole} \mathrm{K}^{2}$. 


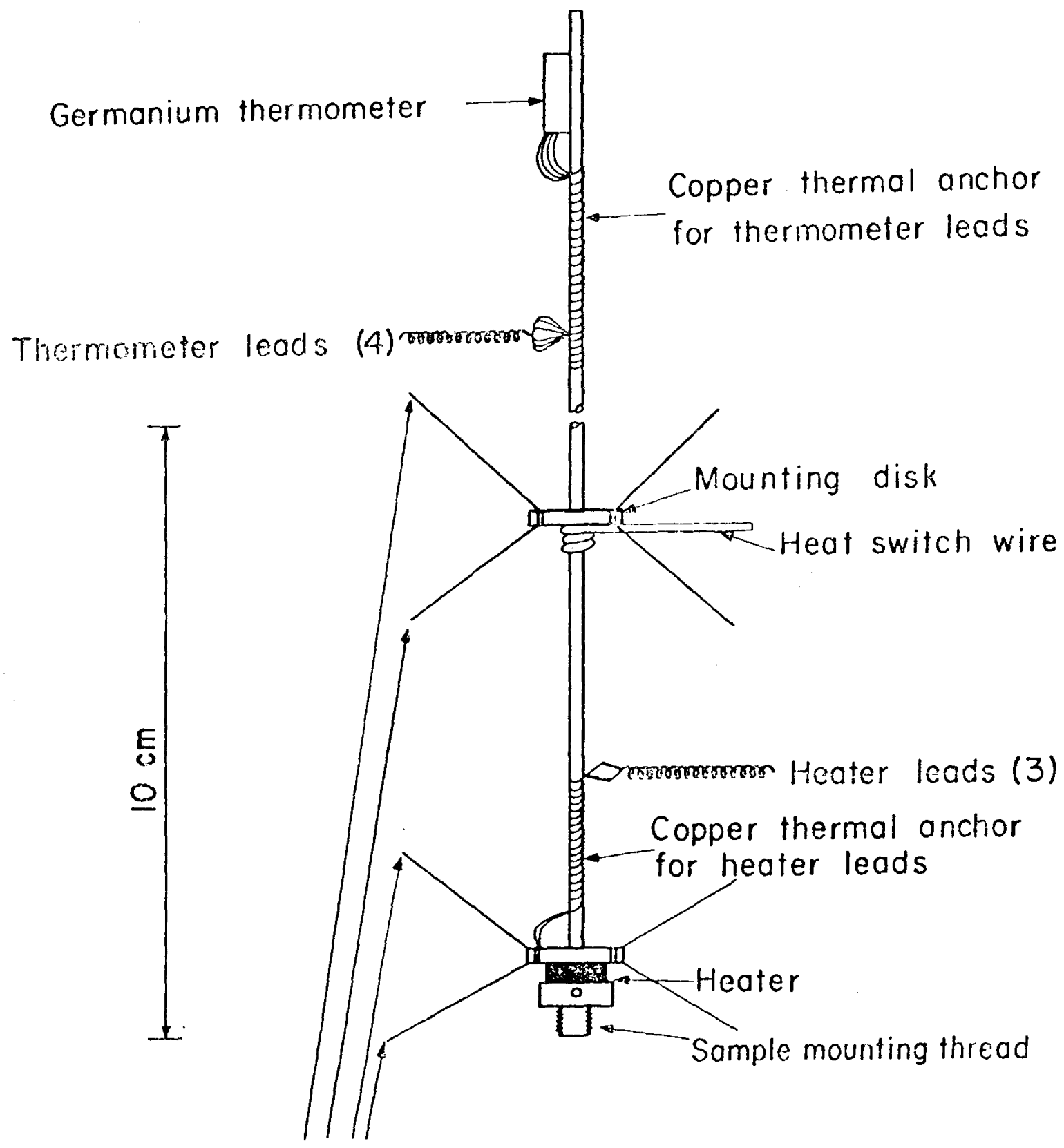

Nylon monofilament

Figure 1 


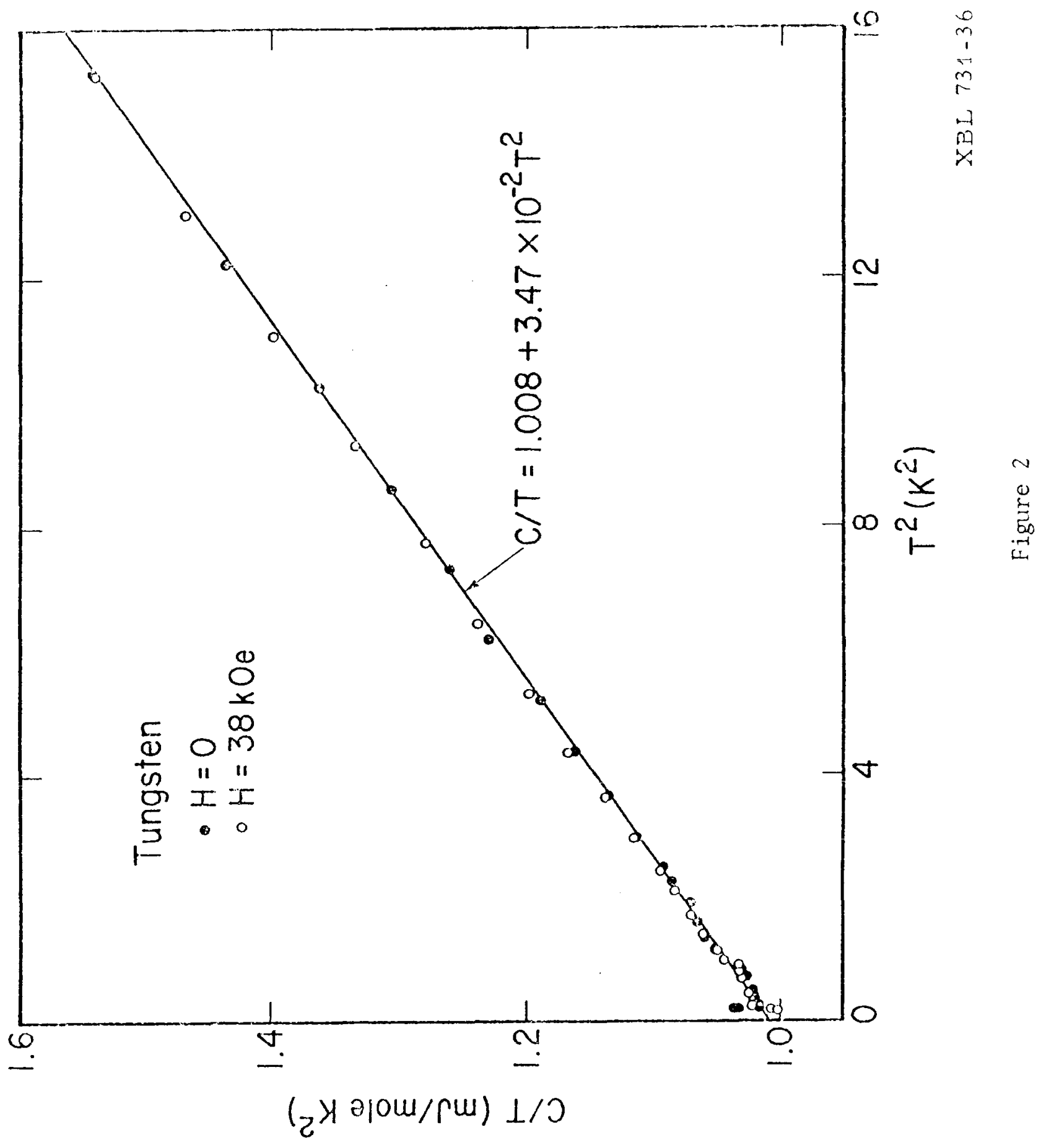




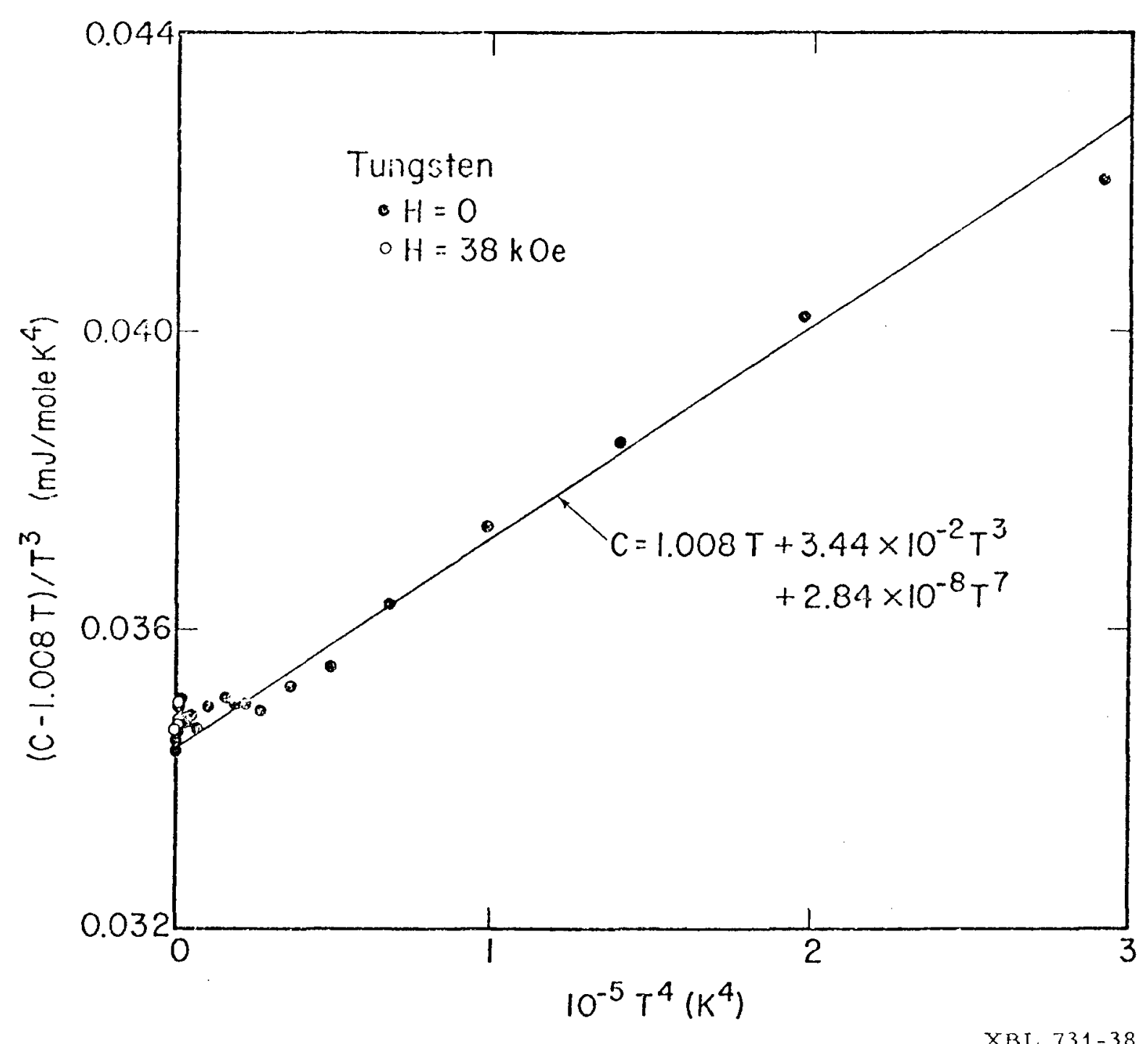

Figure 3 


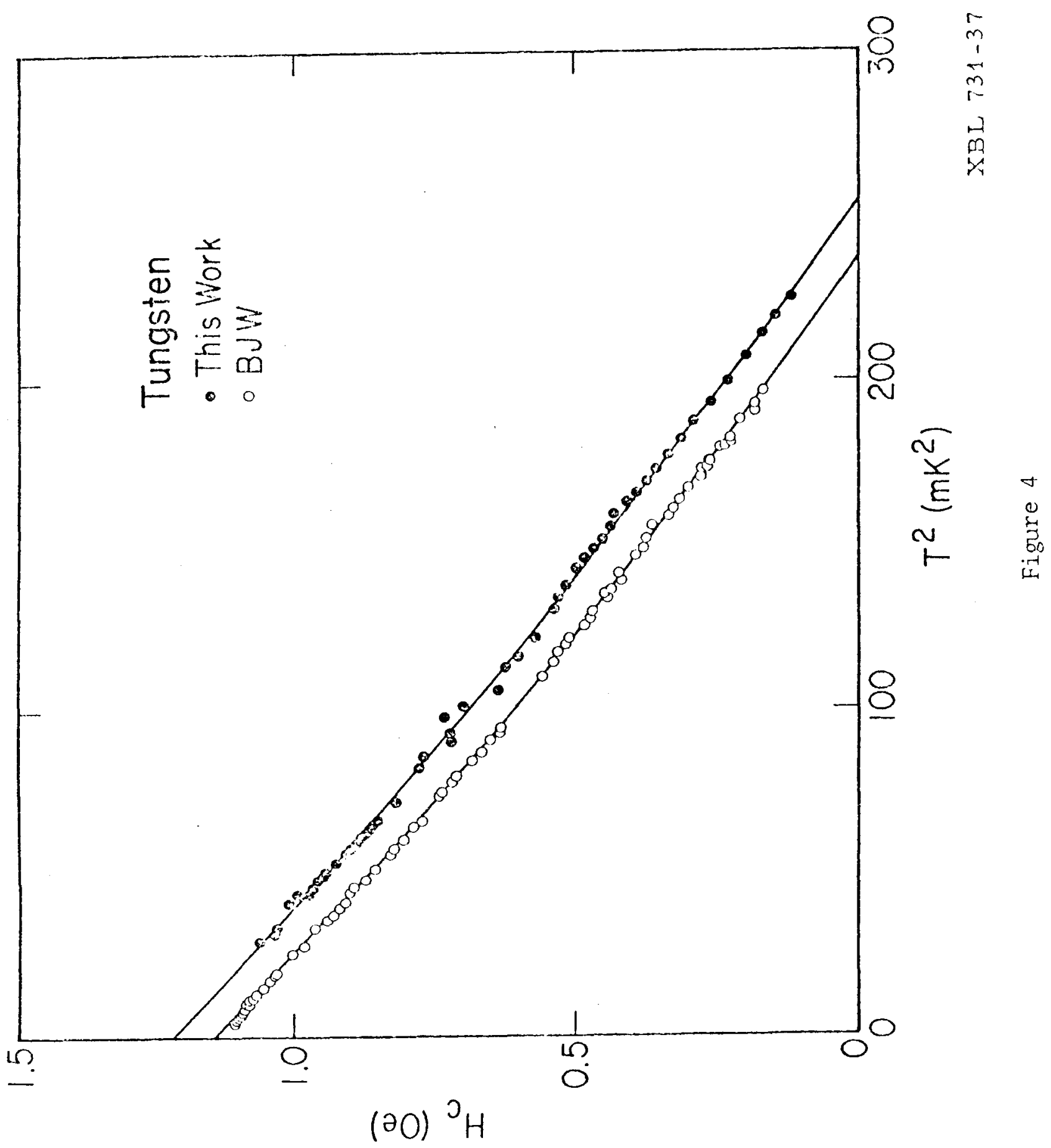




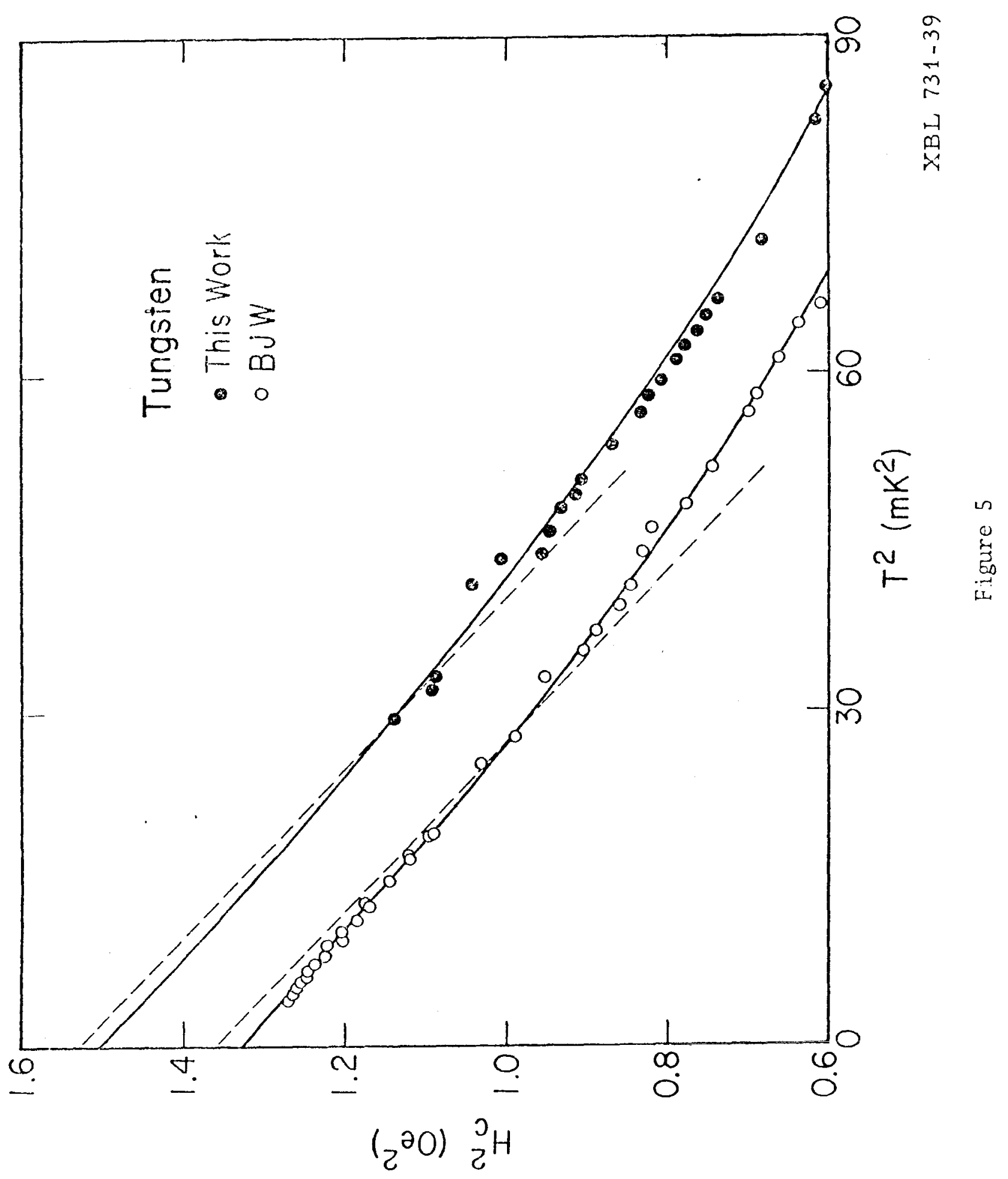




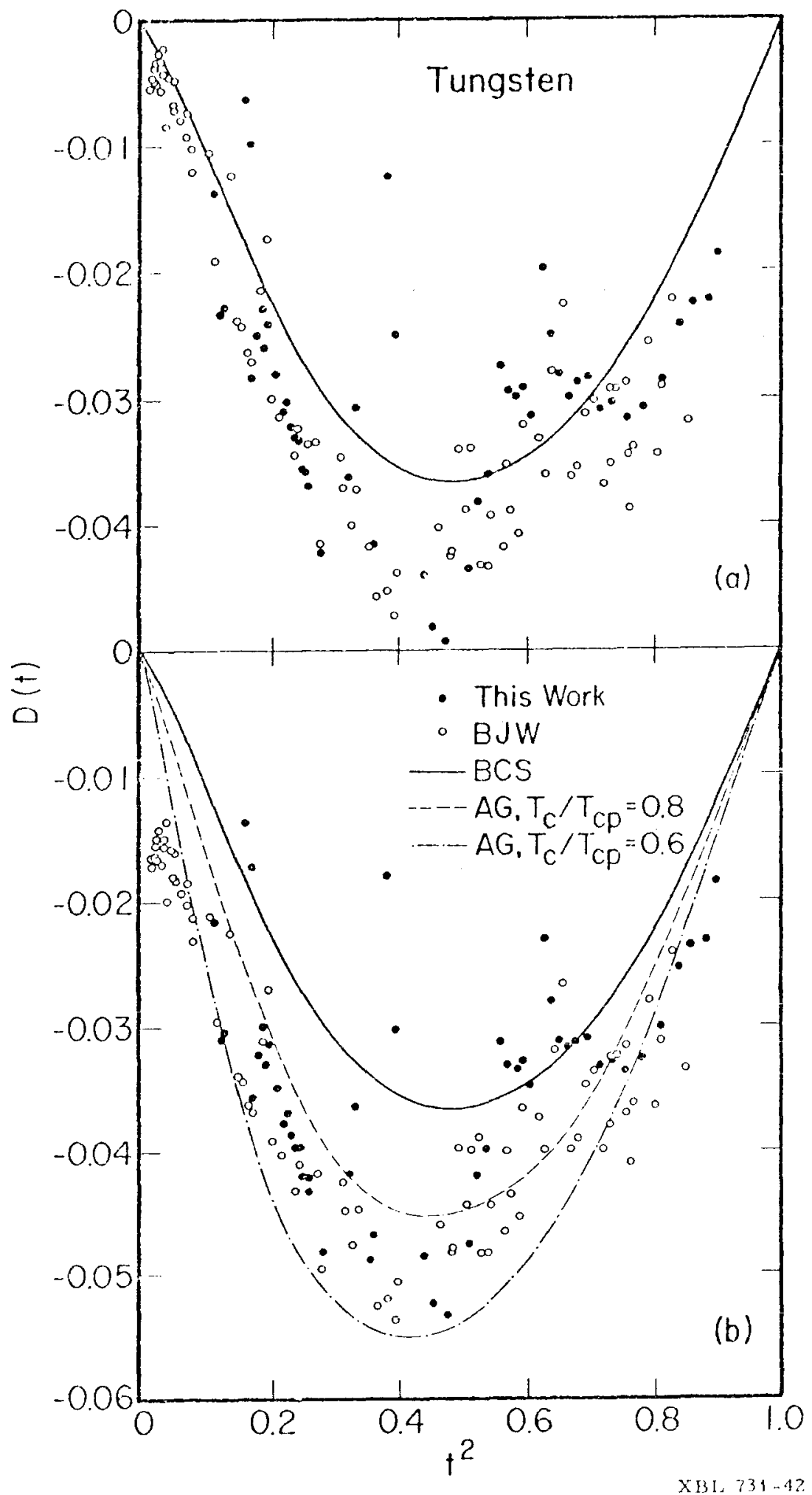

IFgure 6 


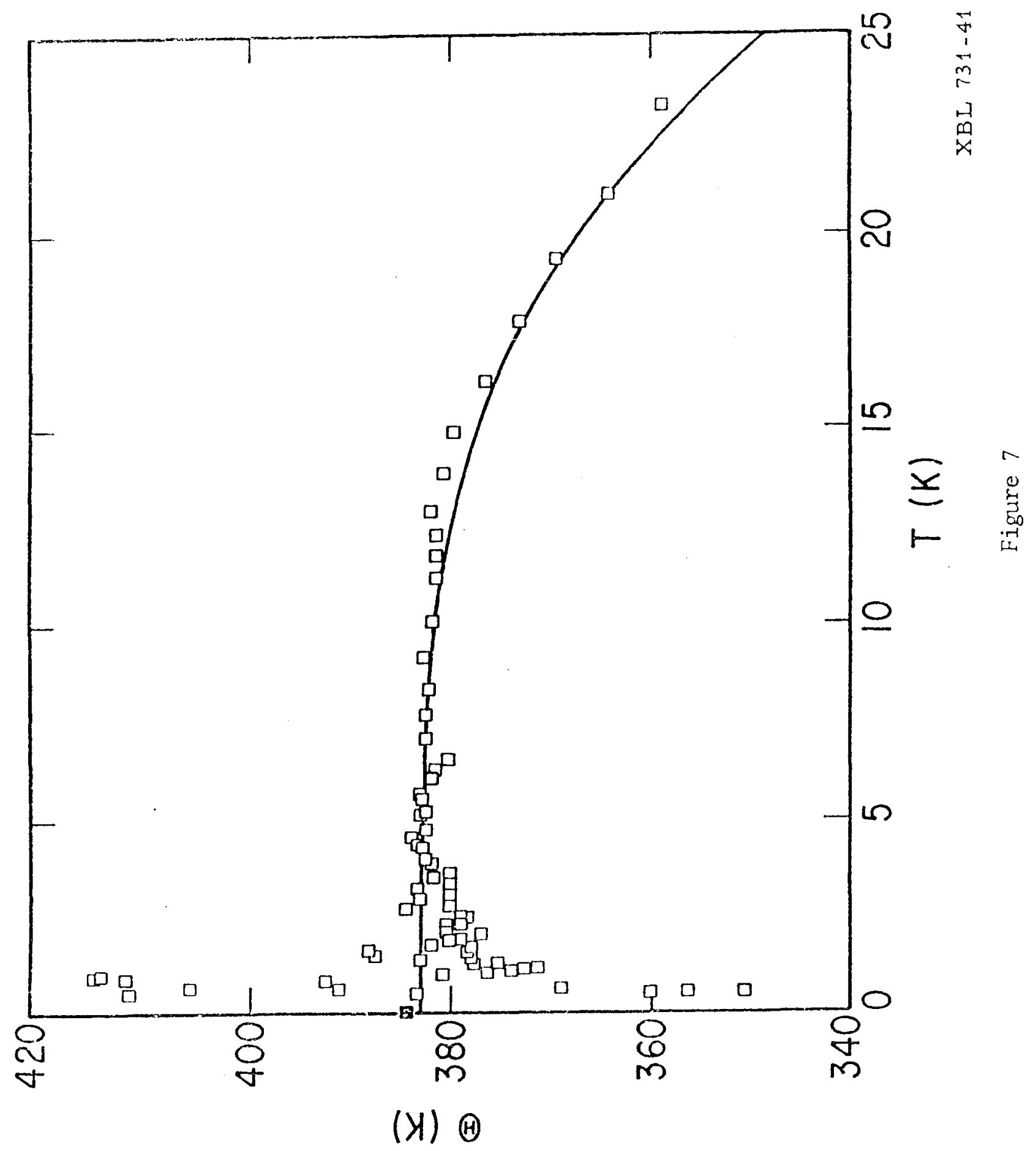




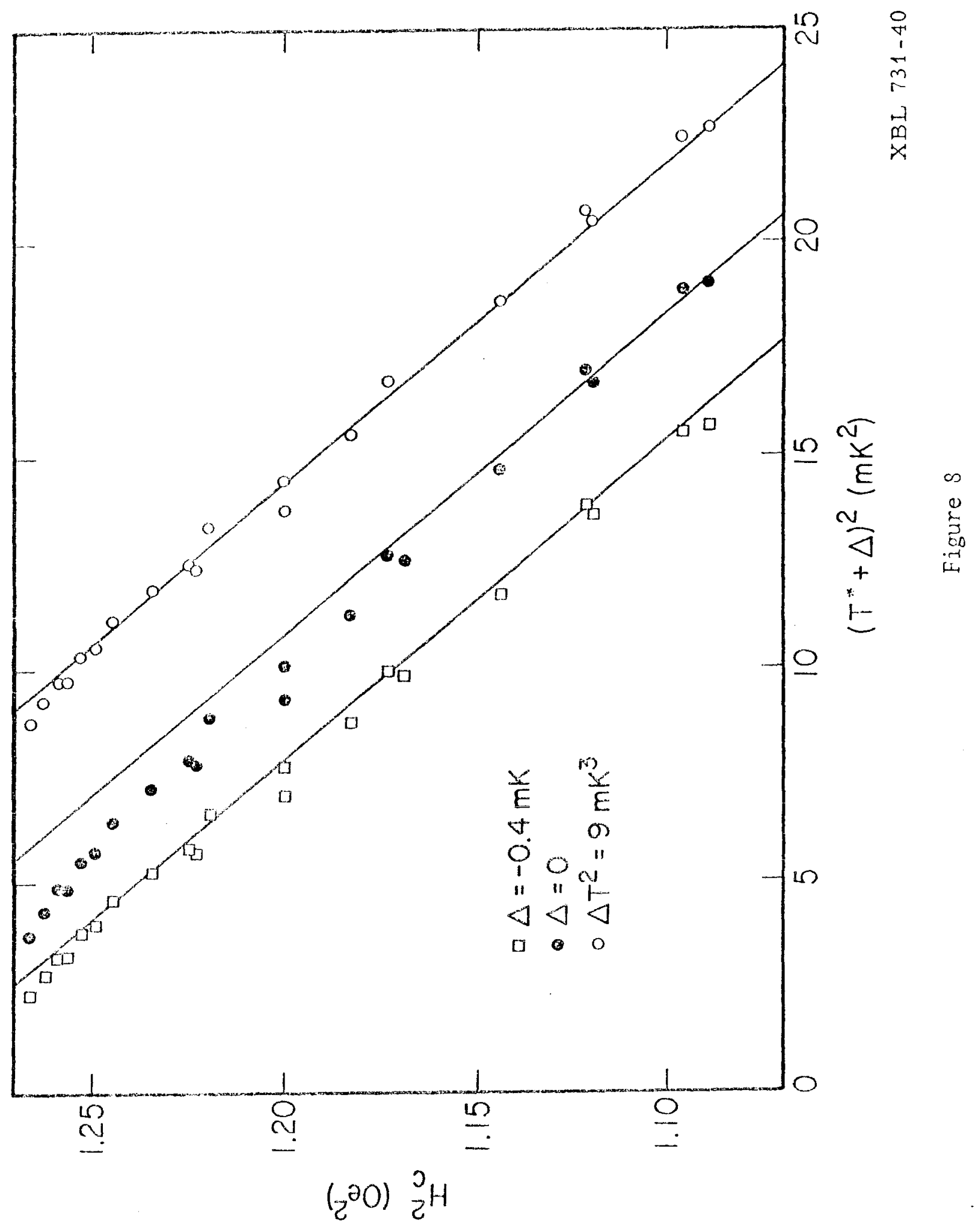

